\title{
Hot and retro meet Arabidopsis
}

\author{
Rocio Escobar-Guzmán, Stefan De Folter and Nayelli Marsch-Martínez* \\ Laboratorio Nacional de Genómica para la Biodiversidad, Centro de Investigación y de Estudios Avanzados del Instituto Politécnico Nacional, Irapuato, \\ Guanajuato, México \\ *Correspondence: nmarsch@ira.cinvestav.mx
}

\section{A commentary on}

An siRNA pathway prevents transgenerational retrotransposition in plants subjected to stress

by Ito, H., Gaubert, H., Bucher, E., Mirouze, M., Vaillant, I., and Paszkowski, J. (2011). Nature 472, 115-119.

The most abundant transposable elements (TE) in the eukaryotic genomes are retrotransposons, which are suppressed by host epigenetic mechanisms, preventing their uncontrolled propagation (Slotkin and Martienssen, 2007; Lisch and Bennetzen, 2011). All known plant retrotransposons remain quiescent during development but are activated by stresses, such as environmental, wounding, pathogen attack, and cell culture (Wessler, 1996). An intriguing aspect in plants exposed to stress is how they control the accumulation and transposition of TE and prevent transgenerational transposition. In the last years, it has been shown that not only stress but also developmental cues, such as male and female gametophyte development trigger the reactivation of transposons in specific cells and tissues (Mosher et al., 2009; Slotkin et al., 2009; Olmedo-Monfil et al., 2010). For example, in pollen vegetative nuclei but not sperm cells, the chromatin remodeling factor decrease in DNA methylation 1 (DDM1) is downregulated. DDM1 is a master regulator of TE activity in Arabidopsis, involved in TE DNA methylation, histone modification, and $24 \mathrm{nt}$ small interfering RNA (siRNA) production. As a result, transposons are reactivated in the vegetative nucleus, and the siRNAs that are produced move to the sperm cell to suppress transposons and protect the germline (Slotkin et al., 2009). siRNA pathways in plants play an important role in the control of transposition (Kasschau et al., 2007). However, the role of siRNA biogenesis in controlling transgenerational transposition was not completely clear because transposons remained immobile during inbreeding of mutants affected in this pathway (Mosher et al., 2009).
Using elegant experiments, Ito et al. (2011) were able to demonstrate that a siRNA pathway is crucial to prevent transgenerational retrotransposition in plants subjected to heat-stress (Ito et al., 2011). The heat-stress treatment consisted of a double-temperature-shift stress: $24 \mathrm{~h}$ at $6^{\circ} \mathrm{C}$ followed by $24 \mathrm{~h}$ at $37^{\circ} \mathrm{C}$. The transcription of a particular family of Ty1/copia-type retrotransposons, named ONSEN, was activated when the seedlings of Arabidopsis were subjected to the heat-stress treatment, going back to pre-heat levels after 3 days. Interestingly, ONSEN transcript levels were higher in heat-stressed mutants affected in siRNA biogenesis [the DNA-dependent RNA polymerase (Pol)IV nrpd1 and nprd2, RNA-dependent RNA polymerase $2 r d r 2$, and Dicer-like 3 dcl 3 mutants] than heatstressed wild-type plants, suggesting that an siRNA pathway plays an important role in restricting ONSEN transcript levels after heat shock treatments. Moreover, DNA analysis by Southern blotting and $\mathrm{qPCR}$ revealed increased accumulation of extrachromosomal ONSEN copies directly after heat-stress. Copy number was considerably higher in nrpd1 mutants than in wild-type plants, reaching about 500 in the mutant compared to 50 in the wild-type. After 20-30 days, ONSEN copy number gradually decreased and returned to the original number. New ONSEN insertions were not detected in the genomic DNA of either heat-stressed wild-type or nrpd1 mutants, suggesting that indeed, the increase in copy number after heat-stress represented most likely extrachromosomal copies. However, in the progeny of self-fertilized nrpd1 plants subjected to heat-stress, a surprisingly high frequency of new insertions was detected, in contrast to control nrpd 1 plants or wild-type plants (control and heatstressed), where any new insertions were found. It has been suggested that siRNAs inactivate transgenerational transposition during gametophyte formation (Slotkin et al., 2009), but an analysis of germinal transposition events had not been reported in support. In contrast, further experiments by Ito et al. (2011) suggested that the new transposition events in the progeny of heat-stressed nrpd1 plants occurred early in flower formation, before the differentiation of female and male gametophytes. The authors suggest that 24-nucleotide siRNAs are responsible for the "resetting" of "stress memory" during somatic growth and/or suppression of retrotransposition in floral tissues. Based on the study of transgenerational transposition in other mutants altered in epigenetic regulation and siRNA biogenesis, they further propose that ONSEN control occurs in two steps that may involve different mechanisms: restricting the levels of transcription and suppressing transgenerational transposition. When the position of the new transposition events was analyzed, the authors discovered that though ONSEN inserted genome wide, it showed a clear preference for inserting in transcribed gene regions, especially in exons. Most remarkably, after Ito et al. (2011) studied the transcription of two genes harboring the new insertions, they found that these genes were now heatresponsive, as also occurred in a natural variant of a gene where an ONSEN copy was present.

After discovering transposons, Barbara McClintock proposed that they were "controlling elements," able to restructure genomes and generate genomic diversity in organisms challenged by stressful situations (discussed in McClintock, 1984). Now, with the increasing knowledge about the molecular mechanisms that control transposition, and by altering specific pathways of epigenetic regulation in combination with environmental triggers, novel strategies to generate useful traits than can be subjected to selection in plant breeding can be designed (Mirouze and Paszkowski, 2011). The findings by Ito et al. (2011) open interesting possibilities to produce useful new stress-controlled alleles. "Activation tagging" populations have been very useful in discovering new gene func- 
tions (reviewed in Marsch-Martinez and Pereira, 2010). However, stress-inducible activation tagging populations have not been developed. With the results presented by Ito et al. (2011), it would seem possible to use the progeny of nrpdl stressed plants as a true natural retrotransposonbased, stress-induced "activation tagging" population.

The work of Ito et al. (2011) represents an exciting topic and enriches our understanding of the processes that control retrotransposition in stressed plants, and the importance of a siRNA pathway in preventing transgenerational transposition.

\section{REFERENCES}

Ito, H., Gaubert, H., Bucher, E., Mirouze, M., Vaillant, I., and Paszkowski, J. (2011). An siRNA pathway prevents transgenerational retrotransposition in plants subjected to stress. Nature 472, 115-119.
Kasschau, K. D., Fahlgren, N., Chapman, E. J., Sullivan, C. M., Cumbie, J. S., Givan, S. A., and Carrington, J. C. (2007). Genome-wide profiling and analysis of Arabidopsis siRNAs. PLoS Biol. 5, e57. doi: 10.1371/ journal.pbio.0050057

Lisch, D., and Bennetzen, J. L. (2011). Transposable element origins of epigenetic gene regulation. Curr. Opin. Plant Biol. 14, 156-161.

Marsch-Martinez, N., and Pereira,A. (2010). "Activation tagging for gain-of-function mutants," in Plant Developmental Biology-Biotechnological Perspectives, eds E.-C. Pua and M. R. Davey (Berlin: SpringerVerlag), 345-370.

McClintock, B. (1984). The significance of responses of the genome to challenge. Science 226, 792-801.

Mirouze, M., and Paszkowski, J. (2011). Epigenetic contribution to stress adaptation in plants. Curr. Opin. Plant Biol. 14, 267-274.

Mosher, R. A., Melnyk, C. W., Kelly, K. A., Dunn, R. M., Studholme, D. J., and Baulcombe, D. C. (2009). Uniparental expression of PolIV-dependent siRNAs in developing endosperm of Arabidopsis. Nature 460, 283-286.

Olmedo-Monfil, V., Duran-Figueroa, N., ArteagaVazquez, M., Demesa-Arevalo, E., Autran, D., Grimanelli, D., Slotkin, R. K., Martienssen, R. A., and
Vielle-Calzada, J. P. (2010). Control of female gamete formation by a small RNA pathway in Arabidopsis. Nature 464, 628-632.

Slotkin, R. K., and Martienssen, R. (2007). Transposable elements and the epigenetic regulation of the genome. Nat. Rev. Genet. 8, 272-285.

Slotkin, R. K., Vaughn, M., Borges, F., Tanurdzic, M., Becker, J. D., Feijo, J.A., and Martienssen, R. A. (2009). Epigenetic reprogramming and small RNA silencing of transposable elements in pollen. Cell 136, 461-472. Wessler, S. R. (1996). Turned on by stress. Plant retrotransposons. Curr. Biol. 6, 959-961.

Received: 01 June 2011; accepted: 09 June 2011; published online: 21 June 2011.

Citation: Escobar-Guzmán R, De Folter S and MarschMartinez N (2011) Hot and retro meet Arabidopsis. Front. Plant Sci. 2:22. doi: 10.3389/fpls.2011.00022

This article was submitted to Frontiers in Plant Genetics and Genomics, a specialty of Frontiers in Plant Science. Copyright $\odot 2011$ Escobar-Guzmán, De Folter and MarschMartinez. This is an open-access article subject to a nonexclusive license between the authors and Frontiers Media $S A$, which permits use, distribution and reproduction in other forums, provided the original authors and source are credited and other Frontiers conditions are complied with. 